\title{
Uso de corticóide como inibidor da resposta inflamatória sistêmica induzida pela circulação extracorpórea
}

\author{
Luiz Antonio BRASIL*, Walter José GOMES ${ }^{* *}$, Reinaldo SALOMÃO**, José Honório Palma FONSECA ${ }^{* *}$, \\ João Nelson Rodrigues BRANCO**, Enio BUFFOLO ${ }^{\star \star}$
}

RBCCV 44205-467

Brasil L A, Gomes W J, Salomão R, Fonseca J H P, Branco J N R, Buffolo E - Uso de corticóide como inibidor da resposta inflamatória sistêmica induzida pela circulação extracorpórea. Rev Bras Cir Cardiovasc 1999; 14 (3): 254-68.

RESUMO: A circulação extracorpórea (CEC) propicia o desenvolvimento de uma Síndrome de Resposta Inflamatória Sistêmica, com liberação de citocinas responsáveis por várias manifestações clínicas.

Objetivo: Observar a liberação das citocinas Fator de Necrose Tumoral Alfa (TNF $\alpha$ ) e Interleucina 6 (IL6) e verificar as alterações clínicas produzidas em pacientes submetidos à revascularização do miocárdio com CEC, utilizando ou não corticóide.

Casuística e Métodos: Foram estudados 30 pacientes, sendo 15 (Grupo I) com uso de corticóide (Metilprednisolona, $30 \mathrm{mg} / \mathrm{kg}$ ) e 15 (Grupo II) sem uso de corticóide. Amostras sangüíneas seriadas foram colhidas, sendo analisadas a liberação de TNF $\alpha$ e IL-6, contagem de leucócitos, VHS e glicemia. Foram comparadas a pressão arterial, freqüência cardíaca, temperatura, sangramento pós-operatório, tempo de intubação orotraqueal e necessidade de drogas vasoativas. Na análise estatística foram considerados significativos valores de $p \leq 0,05$.

Resultados: No Grupo I o TNF $\alpha$ não foi detectado e a IL-6 foi detectada em 13 pacientes, com níveis variando de 8,6 a 101,8 pg/ml. No Grupo II o TNF $\alpha$ foi detectado em 13 pacientes, com níveis entre 5,4 e 231,0 $\mathrm{pg} / \mathrm{ml}$. A IL-6 neste grupo foi detectada nos 15 pacientes, sendo seus níveis mais elevados que aqueles encontrados no Grupo I, variando entre 5,5 e 2569,0 pg/ml. Os pacientes do Grupo I apresentaram pressão arterial média mais elevada $(7,9 \pm 0,5 \mathrm{vs} 7,3 \pm 0,4 \mathrm{mmHg})$, menor necessidade de drogas vasoativas (5 vs 11$)$. Evoluíram com menos taquicardia ( $105,6 \pm 5,9$ vs $109,3 \pm 7,2 \mathrm{bpm})$, temperatura menos elevada ( $36,5 \pm 0,2$ vs $\left.37,3 \pm 0,2^{\circ} \mathrm{C}\right)$, menor sangramento pós-operatório $(576,6 \pm 119,5$ vs $810,0 \pm 176,2 \mathrm{ml})$, menor tempo de intubação orotraqueal $(11,0 \pm 2,0$ vs $14,6 \pm 2,9$ h) e leucocitose menos acentuada. Os níveis de glicemia só foram significativos (Grupo I > Grupo II) nas amostras colhidas no PO imediato e 1ํPO. O VHS não apresentou diferença estatisticamente significativa entre os dois grupos.

Conclusões: A metilprednisolona inibiu significantemente a liberação de citocinas pró-inflamatórias principalmente o TNF $\alpha$. Os efeitos sistêmicos adversos decorrentes da reação inflamatória pós-CEC foram atenuados com o uso do corticóide.

DESCRITORES: Revascularização miocárdica. Circulação extracorpórea, efeito adverso. Corticóides, farmacologia. Síndrome séptica, etiologia. IL6, antagonistas \& inibidores. TNF-alfa, antagonistas \& inibidores.

\footnotetext{
Trabalho realizado na Disciplina de Cirurgia Cardiovascular, da Escola Paulista de Medicina da Universidade Federal de São Paulo, São Paulo, SP, Brasil. Apresentado ao 26ํㅡㄹ Congresso Nacional de Cirurgia Cardíaca. Fortaleza, CE, 8 a 10 de abril, 1999.

* Da Universidade Federal de Goiás

** Da Escola Paulista de Medicina da Universidade Federal de São Paulo

Endereço para correspondência: Luiz Antonio Brasil. Rua T-53, 235. Setor Marista. Goiânia, GO, Brasil. CEP 74.150-310. Tel. (062) 2413997.

Fax (062) 241 0377. e-mail: labrasil@cardiol.br
} 
Brasil L A, Gomes W J, Salomão R, Fonseca J H P, Branco J N R, Buffolo E - Uso de corticóide como inibidor da resposta inflamatória sistêmica induzida pela circulação extracorpórea. Rev Bras Cir Cardiovasc 1999; 14 (3): 254-68.

\section{INTRODUÇÃO}

A circulação extracorpórea (CEC) proporcionou um grande avanço da cirurgia cardíaca em todo o mundo, tornando-se um procedimento essencial para abordagem de uma série de cardiopatias, até então, sem possibilidades de terapêutica cirúrgica.

Por ser um procedimento que não mantém os princípios da fisiologia normal, sua utilização rotineira estimulou o estudo das complicações a ela associadas.

O fluxo não pulsátil; o trauma dos elementos sangüíneos ocasionado pelas bombas de roletes, filtros e aspiradores; as substâncias que são incorporadas ao perfusato; as trocas gasosas modificadas pelos oxigenadores; as variações de temperatura e, sobretudo, a exposição do sangue a superfícies artificiais provocam efeitos sistêmicos adversos que propiciam, a cada dia, esforços no sentido de aperfeiçoar o sistema coração-pulmão artificial.

Apesar do avanço da indústria biomédica meIhorando progressivamente a qualidade dos equipamentos e materiais empregados no conjunto coração-pulmão artificial, e embora a mortalidade dos pacientes operados com CEC atualmente seja bai$x a$, ainda hoje, a CEC não está totalmente isenta de complicações, tendo influência direta na morbidade dos pacientes (1).

Está comprovado que a CEC é responsável pelo desenvolvimento de uma Síndrome de Resposta Inflamatória Sistêmica (SIRS), também denominada de síndrome pós-perfusão, com presença de leucocitose, aumento da permeabilidade vascular levando ao acúmulo de líquido intersticial, associada a lesões orgânicas, principalmente no coração e pulmões, contribuindo com o aumento da morbidade pós-operatória(1,2).

Clinicamente a síndrome de resposta inflamatória sistêmica pós-CEC se caracteriza pelo comprometimento das funções pulmonares, renais, cerebrais, cardíacas, presença de febre, taquicardia, hipotensão arterial, leucocitose, coagulopatia, suscetibilidade às infecções, alteração da permeabilidade vascular levando ao acúmulo de líquido intersticial, vasoconstricção e hemólise ${ }^{(1,2)}$.

Em reunião realizada pelo American College of Chest Physicians / Society of Critical Care Medicine (3) ficou definida que a SIRS é uma resposta do organismo a uma variedade de agressões graves (infecciosas ou não), com presença de duas ou mais das seguintes condições:

- Temperatura $>38^{\circ} \mathrm{C}$.

- Freqüência cardíaca $>90$ batimentos por minuto.

- Freqüência respiratória > 20 incursões respiratórias por minuto. $\checkmark \mathrm{PCO}_{2}$ (tensão do dióxido de carbono) $<32 \mathrm{mmHg}$ (milímetros de mercúrio).

- Número de leucócitos > $12.000 \mathrm{~mm}^{3}$ (milímetros cúbicos), ou menor que $4.000 \mathrm{~mm}^{3}$, ou bastões $>10 \%$ dos neutrófilos.

TAYLOR(4) relatou que a SIRS não é uma entidade clínica única, apresentando um espectro de resposta de moderada a grave, que seria induzida em todos os pacientes submetidos à circulação extracorpórea, com grau de intensidade variável de paciente para paciente.

Como fatores causais desta síndrome pósperfusão incluímos o trauma cirúrgico, o contato do sangue com superfícies não endotelizadas do circuito extracorpóreo e as lesões de reperfusão após o término da $\operatorname{CEC}^{(1,2,5)}$.

O contato do sangue com as superfícies não biológicas do circuito extracorpóreo provoca uma reação do sistema humoral e celular sangüíneos, desencadeando a ativação do sistema complemento, de fatores da coagulação, da fibrinólise, da cascata de calicreínas e dos neutrófilos, ocasionando a liberação de mediadores inflamatórios, que induzem a liberação de enzimas proteolíticas e produção de radicais livres de oxigênio ${ }^{(1,2,6)}$.

A reação do sistema humoral e celular decorrente do uso da CEC é semelhante à reação produzida pelas endotoxinas nas sepses gram-negati$\operatorname{vas}^{(4,7,8)}$. Estudos têm demonstrado a presença de endotoxinas na $\operatorname{CEC}^{(9,10)}$.

Dentre os mediadores inflamatórios liberados na SIRS estão as moléculas de adesão (selectinas, integrinas e imunoglobulinas), o óxido nítrico, os produtos do metabolismo do ácido aracdônico (Tromboxane A2, prostaglandinas e os leucotrienos), o fator ativador plaquetário (PAF) e, principalmente, as citocinas.

As citocinas são glicoproteínas produzidas por uma variedade de células, sobretudo as mononucleares, que agem em nível local e sistêmico, controlando diversos processos de natureza hormonal, imune e inflamatória. Elas funcionam como mensageiros intercelulares e atuam como um dos principais mediadores da resposta inflamatória, sendo responsáveis por lesões vasculares e por disfunções orgânicas verificadas na sepse e após a circulação extracorpórea(11,12).

As citocinas são produzidas na dependência da estimulação por algum agente, havendo pouca ou nenhuma estocagem nas células produtoras. Depois de liberadas, as citocinas agem intermediadas por receptores de membrana específicos, modulando a produção e atividade de outras citocinas, bem como de outras substâncias importantes na resposta in- 
Brasil L A, Gomes W J, Salomão R, Fonseca J H P, Branco J N R, Buffolo E - Uso de corticóide como inibidor da resposta inflamatória sistêmica induzida pela circulação extracorpórea. Rev Bras Cir Cardiovasc 1999; 14 (3): 254-68.

flamatória. A produção de citocinas é estimulada por endotoxinas, sistema complemento ativado, imunocomplexos e por proteínas de superfície que surgem por dano na integridade do endotélio vascu$\operatorname{lar}^{(13,14)}$.

Quando pequenas quantidades de citocinas são liberadas nos tecidos, predominam os efeitos benéficos, determinando uma ativação dos mecanismos de defesa do organismo contra o agente agressor, mas a produção excessiva desses mediadores provocam efeitos maléficos ao organismo(15).

O fator de necrose tumoral alfa (TNF $\alpha$ ), a interleucina 1 (IL-1) e a interleucina 6 (IL-6) são exemplos de citocinas consideradas pró-inflamatórias que estão envolvidas na SIRS pós-CEC, sendo liberadas em função da ativação do sistema complemento, após o contato do sangue com a superfície artificial do circuito extracorpóreo ou por ação de endotoxinas, causando importantes alterações fisiopatológicas ao $\operatorname{organismo}^{(16,17)}$

HOLZHEIMER et al. ${ }^{(18)}$ estudaram a detecção simultânea de TNF $\alpha$ e IL-6 e demonstraram que estas citocinas produzidas pelos neutrófilos ativados estimulam a adesão dos neutrófilos nos miócitos cardíacos, exercendo um importante papel na mediação dos danos miocárdicos verificados após a CEC.

HENNEIN et al. ${ }^{(19)}$ relacionaram os níveis séricos de TNF $\alpha$, IL-6 e IL-8 com as alterações da função ventricular esquerda e isquemia miocárdica, e sugeriram que estas citocinas são responsáveis pela depressão miocárdica no pós-operatório de pacientes operados com CEC.

Em estudo recentemente publicado(20), tivemos oportunidade de comparar pacientes submetidos à cirurgia de revascularização do miocárdio com e sem emprego de circulação extracorpórea (Grupo I e Grupo II, respectivamente). No Grupo I houve detecção de TNF- $\alpha$ em $60 \%$ dos pacientes contra $0 \%$ no Grupo II $(p<0,05)$, demonstrando o papel da CEC na ativação do TNF- $\alpha$. Além disso, os pacientes do Grupo I evoluíram com hipotensão arterial mais acentuada, havendo maior necessidade do uso de drogas vasoativas, apresentaram freqüência cardíaca e temperatura mais elevadas, maior sangramento pós-operatório, tempo de intubação orotraqueal mais prolongado e maior leucocitose.

Baseados nestes dados, estamos agora propondo o bloqueio da reação inflamatória sistêmica induzida pela circulação extracorpórea, com uso de um inibidor, a metilprednisolona, para observar a liberação de citocinas (TNF- $\alpha$ e Interleucina - 6) e verificar as alterações clínicas produzidas num grupo de pacientes com a utilização do inibidor e em outro grupo sem o inibidor.

O objetivo do presente estudo é estudar a libe- ração de citocinas (TNF- $\alpha$ e IL-6) e verificar as alterações clínicas produzidas em pacientes submetidos à cirurgia de revascularização do miocárdio com uso de circulação extracorpórea em pacientes recebendo ou não corticóide.

\section{CASUÍSTICA E MÉTODOS}

No período compreendido entre julho de 1997 e fevereiro de 1998, 30 pacientes portadores de insuficiência coronária foram selecionados para a realização deste estudo prospectivo.

O projeto da pesquisa foi previamente analisado e aprovado pela Comissão de Ética Médica da Instituição.

Foram excluídos do estudo os pacientes portadores de diabete melito, doença pulmonar obstrutiva crônica (DPOC), doença inflamatória crônica, doença hematológica, hepática, renal ou digestiva, e aqueles que apresentavam evidência clínica / laboratorial de infecção. Também foram excluídos os casos de reoperação e os pacientes que faziam uso prévio de betabloqueadores, corticosteróides, ácido acetilsalicílico ou qualquer tipo de antiinflamatório não hormonal.

Os pacientes foram submetidos de maneira consecutiva à operação de revascularização do miocárdio com circulação extracorpórea. Todos os pacientes foram operados no Hospital São Paulo, pela equipe cirúrgica da Disciplina de Cirurgia Cardiovascular da Universidade Federal de São Paulo - Escola Paulista de Medicina (UNIFESP-EPM).

Os 30 pacientes foram divididos em dois Grupos:

Grupo I: 15 pacientes nos quais, após a indução anestésica, foi administrado corticóide (succinato sódico de metilprednisolona $30 \mathrm{mg} / \mathrm{kg}$ ), diluído em $250 \mathrm{ml}$ de soro glicosado $5 \%$, com tempo de infusão de 30 minutos.

Grupo II: 15 pacientes operados sem uso de corticóide.

Antibioticoterapia profilática foi realizada em todos os pacientes de acordo com as normas da Comissão de Controle de Infecção Hospitalar do Hospital São Paulo, com a administração de $2 \mathrm{~g}$ de cefazolina, uma hora antes da operação e, em se-

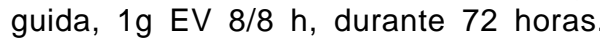

A técnica anestésica empregada seguiu a rotina do Serviço, com indução através de midazolam $(0,1 \mathrm{mg} / \mathrm{kg})$, citrato de fentanil $(2-5 \mathrm{mcg} / \mathrm{kg}) \mathrm{e}$ curarização com brometo de pancurônio $(0,1 \mathrm{mg} / \mathrm{kg})$. A anestesia foi mantida com fentanil em bolus ( $5 \mathrm{mcg} /$ $\mathrm{kg})$, midazolam $(0,1 \mathrm{mg} / \mathrm{kg})$ a cada hora, e inalação 
Brasil L A, Gomes W J, Salomão R, Fonseca J H P, Branco J N R, Buffolo E - Uso de corticóide como inibidor da resposta inflamatória sistêmica induzida pela circulação extracorpórea. Rev Bras Cir Cardiovasc 1999; 14 (3): 254-68.

de isoflurano $(0,5 \%-1,25 \%)$. Todos os pacientes foram mantidos sob ventilação mecânica, com oxigênio a $100 \%\left(\mathrm{FiO}_{2} 100 \%\right)$ e o relaxamento muscular foi obtido com doses de $0,1 \mathrm{mg} / \mathrm{kg}$ de brometo de pancurônio a cada hora.

A abordagem cirúrgica em todos os pacientes foi através de esternotomia mediana.

Como método de proteção miocárdica foi utilizada cardioplegia sangüínea hipotérmica anterógrada intermitente (a cada 15 minutos), associada a hipotermia sistêmica moderada $\left(28^{\circ}-30^{\circ} \mathrm{C}\right)$.

\section{Técnica de Circulação Extracorpórea}

Todos os pacientes foram operados com 0 mesmo equipamento de CEC. O oxigenador utilizado foi o de membranas (OXIM II - 34, fabricado pela Macchi-Baxter Engenharia Biomédica Ltda, São Paulo / SP - Brasil), acompanhado de reservatórios de cardiotomia e de cardioplegia, filtros de linha arterial e de cardioplegia. As cânulas arterial e venosa, bem como os tubos das linhas arterial e venosa eram constituídos de polivinil siliconizado (cloreto de polivinila).

Todo o material artificial descartável empregado na CEC não possuía revestimento de heparina (circuito não heparinizado).

O circuito extracorpóreo foi previamente lavado com solução de Ringer lactato, desprezada antes da colocação do perfusato definitivo.

A composição do perfusato dependeu das condições prévias de cada paciente, e a hemodiluição total foi empregada, sempre que possível, com volume de $1500 \mathrm{ml}$ de solução de Ringer lactato. Acréscimos de sangue ao perfusato foram realizados quando necessário, no sentido de manter o hematócrito entre $26 \%$ e $30 \%$.

Em todos os pacientes a CEC foi instalada com canulação da aorta ascendente e drenagem venosa através de cava única, após heparinização sistêmica com $4 \mathrm{mg} / \mathrm{kg}$, repetida de acordo com o TCA (tempo de coagulação ativado), com o objetivo de mantêlo acima de 450 segundos.

A neutralização da heparina foi realizada em todos os casos com infusão lenta de protamina, na dose de $1: 1$, diluída em soro glicosado $5 \%$.

\section{Cuidados Pós-Operatórios}

Ao término da operação, os pacientes ainda sob anestesia geral e em normotermia foram encaminhados para a Unidade de Pós-Operatório de Cirurgia Cardíaca, intubados, e mantidos sob ventilação me- cânica com respiradores ciclados a volume, com $\mathrm{FiO}_{2}$ necessária para manter a $\mathrm{PaO}_{2}$ acima de $100 \mathrm{mmHg}$.

A reposição de volume no pós-operatório foi feita com soluções cristalóides acrescidas de eletrólitos, no sentido de manter bons parâmetros hemodinâmicos, equilíbrio hidroeletrolítico e ácidobásico. A taxa de hemoglobina foi corrigida sempre que esteve abaixo de $9 \mathrm{mg} / \mathrm{dl}$, com infusão de concentrados de glóbulos.

Foram prescritos, concomitantemente, nitratos, analgésicos e mantida a antibioticoterapia profilática. Drogas vasoativas foram usadas quando necessário, para controle e manutenção da função hemodinâmica. Não foram prescritos antiagregantes plaquetários, betabloqueadores ou qualquer tipo de antiinflamatório.

Durante a permanência dos pacientes na Unidade de Pós-Operatório (48h) foram monitorizadas a pressão arterial média, a freqüência cardíaca e a temperatura axilar, de hora/hora até a extubação do paciente e, em seguida, de 2/2horas.

Após o registro destes parâmetros, os valores médios foram calculados para cada paciente. Foram também registrados o volume total de sangramento pós-operatório até a retirada dos drenos e o tempo total de intubação orotraqueal.

\section{Parâmetros Analisados}

Foram comparadas entre os dois grupos as seguintes variáveis: sexo, idade, peso, altura,IMC, tempo total de operação, tempo de CEC, tempo de anóxia e o número de enxertos realizados.

- Parâmetros clínicos e hemodinâmicos: $\mathrm{Na}$ evolução pós-operatória foram comparados entre os dois grupos os seguintes parâmetros: pressão arterial média, freqüência cardíaca, temperatura, sangramento pós-operatório, tempo de intubação orotraqueal e necessidade de drogas vasoativas.

- Parâmetros laboratoriais: Dosagem dos níveis plasmáticos de citocinas (TNF- $\alpha$ e IL-6) realizada pelo método imunoenzimático Elisa (Predicta Enzyme Immunoassay-Genzyme, USA), contagem de leucócitos, velocidade de hemossedimentação (VHS) e glicemia.

\section{Coleta das Amostras Sangüíneas}

Foram colhidas amostras sangüíneas seriadas da artéria radial ou da linha arterial da CEC durante a perfusão, para a dosagem das citocinas, dos leucócitos e VHS. O sangue colhido $(10 \mathrm{ml})$ foi dividido em dois tubos com EDTA (ácido etilenodiaminotetraacético), sendo um tubo enviado pron- 
Brasil L A, Gomes W J, Salomão R, Fonseca J H P, Branco J N R, Buffolo E - Uso de corticóide como inibidor da resposta inflamatória sistêmica induzida pela circulação extracorpórea. Rev Bras Cir Cardiovasc 1999; 14 (3): 254-68.

tamente ao laboratório para dosagem dos leucócitos e do VHS. No outro tubo, após centrifugação com 7000 rpm durante 10 minutos, foi separado o plasma e dividido em alíquotas de $0,5 \mathrm{ml}$ em tubos de polipropileno apirogênicos, e armazenado em congelador a $70^{\circ} \mathrm{C}$ negativos, até a realização do teste para dosagens do TNF $\alpha$ e IL-6.

O tempo de coleta das amostras sangüíneas foi pré-determinado, sendo o seguinte:

$\Rightarrow$ amostra 1 (A1)- após a indução anestésica (précorticóide e pré-CEC)

$\Rightarrow$ amostra 2 (A2)- durante a CEC (20 minutos após o pinçamento aórtico)

$\Rightarrow$ amostra 3 (A3)- durante a CEC (após o despinçamento aórtico e recuperação dos batimentos cardíacos)

$\Rightarrow$ amostra 4 (A4)- no final da operação

$\Rightarrow$ amostra 5 (A5)- 12 horas de pós-operatório

Os níveis de glicemia foram analisados no préoperatório (A1), no pós-operatório imediato (A2), no 1 P.O. (A3), no $2^{\circ}$ P.O. (A4) e no $3^{\circ}$ P.O. (A5).

\section{Método Estatístico}

Para a análise estatística dos resultados foram aplicados os seguintes testes: "t" de Student, MannWhitney, Qui-quadrado e a Análise de Variância por Postos de Friedman. Em todos os testes fixou-se em 0,05 ou $5 \%(\alpha \leq 0,05)$ o nível de rejeição da hipótese de nulidade.

\section{RESULTADOS}

A análise dos grupos quanto ao sexo mostrou no Grupo I 9 (60\%) pacientes do sexo masculino e 6 $(40 \%)$ do sexo feminino. No Grupo II houve predomínio do sexo masculino com 10 (66,7\%) pacientes e $5(33,3 \%)$ pacientes eram do sexo feminino.

A idade em anos, no Grupo I, variou de 42 a 80 anos (média: 61,1 $\pm 11,7$ anos) e no Grupo II, de 40 a 75 anos (média: 62,0 \pm 9,4 anos).

O peso em quilogramas $(\mathrm{kg})$, no Grupo I foi de 56 a 82 kg (média: 65,2 $\pm 7,3 \mathrm{~kg}$ ) e no Grupo II, de 52 a $102 \mathrm{~kg}$ (média: 69,4 \pm 16,9kg).

Quanto à altura em metros $(\mathrm{m})$, ela variou no Grupo I de 1,55 a 1,75m (média: 1,67 \pm 0,06m), e no Grupo II, de 1,60 a 1,82m (média: 1,69 \pm 0,06m). Para melhor avaliação dos grupos quanto a peso e altura, realizamos o cálculo do índice de massa corpórea (IMC), que se traduz pelo peso em quilogramas, dividido pelo quadrado da altura em metros $\left(P / A^{2}\right)$ e obtivemos, no Grupo I, IMC variando de
19,84 a 26,78 (média: 23,3 $\pm 2,1$ ) e, no Grupo II, de 16,98 a 37,47 (média: 24,4 \pm 6,1).

O tempo total de operação em minutos (min) variou, no Grupo I, de 240 a 355 min (média: 285,3 $\pm 35,7 \mathrm{~min}$ ) e, no Grupo II, de 235 a $360 \mathrm{~min}$ (média: 288,6 \pm 35,0 $\mathrm{min}$ ).

O tempo de circulação extracorpórea (CEC) em minutos (min) foi, no Grupo I, de 62 a $126 \mathrm{~min}$ (média: 92,7 \pm 19,2 min) e, no Grupo II, de 45 a 130 min (média: 95,3 \pm 23,7 $\mathrm{min}$ ).

O tempo de anóxia em minutos (min), no Grupo I, variou de 45 a 97 min (média: 66,1 \pm 16,3 $\mathrm{min}$ ) e, no

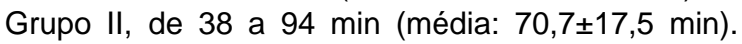

Quanto ao número de enxertos realizados nos pacientes dos dois grupos, tivemos, no Grupo I, 2 $(13,3 \%)$ pacientes que receberam 2 enxertos, 10 $(66,7 \%)$ pacientes com 3 enxertos e $3(20,0 \%)$ pacientes receberam 4 enxertos. Já no Grupo II, 3 (20,0\%) pacientes receberam 2 enxertos, 7 (46,7\%) pacientes 3 enxertos, 4 (26,7\%) pacientes 4 enxertos e $1(6,6 \%)$ paciente recebeu 5 enxertos. Relacionando o número de enxertos realizados com o total de pacientes operados nos dois grupos, encontramos, no Grupo I, média de 3,1 $\pm 0,6$ enxertos / paciente e, no Grupo II, média de 3,2 $\pm 0,8$ enxertos / paciente.

Todas essas variáveis descritas anteriormente e que foram comparadas entre os dois grupos estão expressas na Tabela 1.

Com relação à liberação e detecção de citocinas pró-inflamatórias (TNF $\alpha$ e IL-6) no Grupo I (pacientes que receberam corticóide), não houve detecção de TNF $\alpha$ em nenhum dos pacientes. Já no Grupo II, $13(86,6 \%)$ pacientes apresentaram positividade para o TNF $\alpha$, com níveis plasmáticos variando de 5,4 a 231 picogramas por mililitros $(\mathrm{pg} / \mathrm{ml})$. Os valores médios de TNF $\alpha$ em cada amostra, detectados somente nos pacientes do Grupo II ( $p<0,001)$, estão demonstrados no Gráfico 1.

A IL-6 foi detectada em 13 (86,6\%) pacientes do Grupo I, com níveis plasmáticos variando de 8,6 a $101 \mathrm{pg} / \mathrm{ml}$. No Grupo II (pacientes que não receberam corticóide), esta citocina foi detectada em todos os $15(100 \%)$ pacientes deste grupo, sendo seus níveis plasmáticos bem mais elevados que aqueles encontrados nos pacientes do Grupo I, variando de 5,5 a $2.569 \mathrm{pg} / \mathrm{ml}$. Os valores médios de IL-6 em cada amostra encontrados nos pacientes dos Grupos I e II demonstram que a liberação dessa citocina foi menos significativa $(p<0,001)$ nos pacientes do Grupo I, operados com uso de metilprednisolona (Gráfico 2).

A análise nos dois grupos, dos valores médios da pressão arterial média (PAM) em milímetros de mercúrio $(\mathrm{mmHg})$, revelou no Grupo I uma variação 
Brasil L A, Gomes W J, Salomão R, Fonseca J H P, Branco J N R, Buffolo E - Uso de corticóide como inibidor da resposta inflamatória sistêmica induzida pela circulação extracorpórea. Rev Bras Cir Cardiovasc 1999; 14 (3): 254-68.

TABELA 1

VARIÁVEIS COMPARADAS ENTRE OS GRUPOS

\begin{tabular}{lccc}
\hline & GRUPO I & GRUPO II & P \\
\hline Sexo & $9 \mathrm{M} 6 \mathrm{~F}$ & $10 \mathrm{M} 5 \mathrm{~F}$ & $\mathrm{~ns}$ \\
Idade (anos) & $61,1 \pm 11,7$ anos & $62,0 \pm 9,4 \mathrm{anos}$ & $\mathrm{ns}$ \\
Peso (quilogramas) & $65,2 \pm 7,3 \mathrm{~kg}$ & $69,4 \pm 16,9 \mathrm{~kg}$ & $\mathrm{~ns}$ \\
Altura (metros) & $1,67 \pm 0,06 \mathrm{~m}$ & $1,69 \pm 0,06 \mathrm{~m}$ & $\mathrm{~ns}$ \\
IMC & $23,3 \pm 2,1$ & $24,4 \pm 6,1$ & $\mathrm{~ns}$ \\
Tempo Operação & $285,3 \pm 35,7 \mathrm{~min}$ & $288,6 \pm 35,0 \mathrm{~min}$ & $\mathrm{~ns}$ \\
Tempo CEC & $92,7 \pm 19,2 \mathrm{~min}$ & $95,3 \pm 23,7 \mathrm{~min}$ & $\mathrm{~ns}$ \\
Tempo Anóxia & $66,1 \pm 16,3 \mathrm{~min}$ & $95,3 \pm 23,7 \mathrm{~min}$ & $\mathrm{~ns}$ \\
NNo Enxertos & $3,1 \pm 0,6 \mathrm{enx}$ & $3,2 \pm 0,8 \mathrm{enx}$ & \\
\hline
\end{tabular}

M -masculino; F- feminino; ns - não significante; min - minutos; enx - enxertos

CEC - circulação extracorpórea; IMC - índice de massa corpórea

entre 7 e $9 \mathrm{mmHg}$ (média: 7,9 $\pm 0,5 \mathrm{mmHg}$ ), e no Grupo II esta variação ocorreu entre 6,5 e $8,5 \mathrm{mmHg}$ (média: 7,3 $\pm 0,4 \mathrm{mmHg}$ ), havendo diferença estatisticamente significativa ( $p<0,005)$ entre os Grupos (Grupo I > Grupo II) (Gráfico 3).

A freqüência cardíaca observada nos dois grupos, segundo seus valores médios em batimentos por minuto (bpm) durante o período de internação dos pacientes na Unidade de Pós-Operatório, variou no Grupo I de 90 a 114bpm (média: 105,6 × 5,9bpm) e no Grupo II de 96 a 120bpm (média: 109,3 \pm 7,2bpm). Apesar dos pacientes do Grupo I apresentarem freqüência cardíaca menos elevada que os pacientes do Grupo II, esta diferença não teve significado estatístico.

O uso de drogas vasoativas (inotrópicas positivas) foi necessário nos casos de instabilidade hemodinâmica, sendo utilizadas na sala de operação ou na Unidade de Pós-Operatório. Dos 15 pacientes do Grupo I que receberam corticóide antes da CEC, $5(33,3 \%)$ pacientes necessitaram de drogas vasoativas. Por outro lado, nos pacientes operados sem corticóide (Grupo II), 11 (73,3\%) deles fizeram uso de drogas vasoativas $(p<0,05)$ (Tabela 2$)$.

GRÁFICO 1

VALORES MÉDIOS DO TNF- $\alpha$ (PICOGRAMAS / MILILITROS)

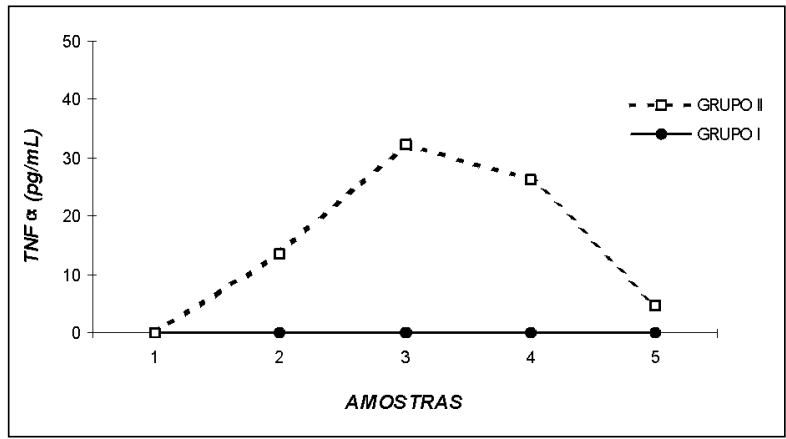

Os valores médios da temperatura em graus Celsius $\left({ }^{\circ} \mathrm{C}\right)$, observados nos pacientes de ambos os grupos, mostraram, no Grupo I, variação entre 36,1 e $36,8^{\circ} \mathrm{C}$ (média: $36,5 \pm 0,2^{\circ} \mathrm{C}$ ). No Grupo II, os valores médios da temperatura estiveram entre 36,8 e $37,5^{\circ} \mathrm{C}$ (média: $37,3 \pm 0,2^{\circ} \mathrm{C}$ ), demonstrando que a temperatura foi significantemente mais elevada $(p<0,001)$ nos pacientes do Grupo II em relação aos pacientes do Grupo I (Gráfico 4)

O total de sangramento no pós-operatório em mililitros ( $\mathrm{ml}$ ) foi mais significativo $(p<0,001)$ no Grupo II em relação ao Grupo I. O total de sangramento no Grupo I variou de 400 a $800 \mathrm{ml}$ (média: $576,6 \pm 119,5 \mathrm{ml}$ ) e no Grupo II foi de 550 a 1200ml (média: $810 \pm 176,2 \mathrm{ml}$ ) (Gráfico 5).

O tempo total de intubação orotraqueal em horas (h) variou no Grupo I de 8 a 15h (média: 11,0 $\pm 2,0 \mathrm{~h}$ ) e no Grupo II esteve entre 10 e 20h (média: 14,6 $\pm 2,8 \mathrm{~h}$ ), demonstrando que os pacientes do Grupo I apresentaram tempo de intubação orotraqueal mais curto ( $p<0,001)$, quando comparados com os pacientes do Grupo II (Gráfico 6).

Observando o número de leucócitos totais de

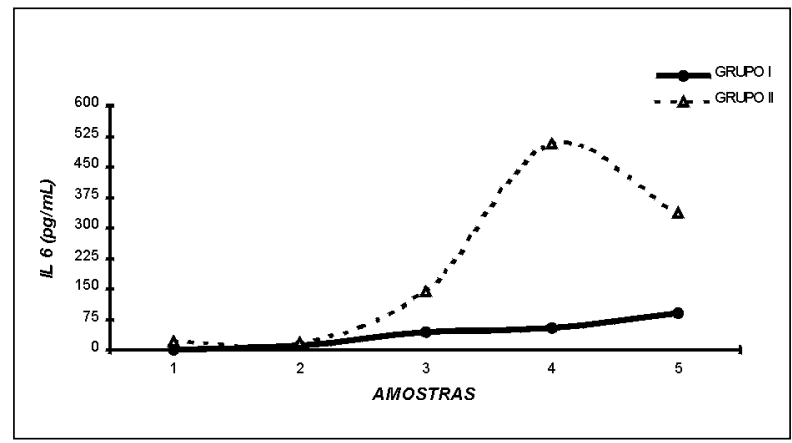


Brasil L A, Gomes W J, Salomão R, Fonseca J H P, Branco J N R, Buffolo E - Uso de corticóide como inibidor da resposta inflamatória sistêmica induzida pela circulação extracorpórea. Rev Bras Cir Cardiovasc 1999; 14 (3): 254-68.

GRÁFICO 3

VALORES MÉDIOS DA PRESSÃO ARTERIAL MÉDIA (MMHG)

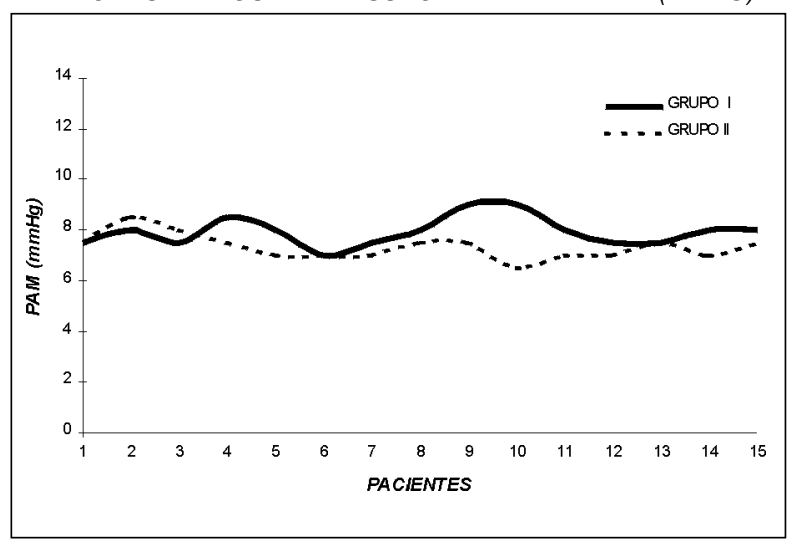

todos os pacientes, em cada tempo, e, em seguida, após o cálculo da média de cada amostra nos Grupos I e II, verificamos que os pacientes dos dois grupos apresentaram leucocitose. Esta leucocitose teve início durante a CEC (A2 e A3) com elevação progressiva após a CEC (A4 e A5), sendo menos acentuada ( $p<0.001$ ) nos pacientes do Grupo I, que fizeram uso de corticóide pré-CEC (Gráfico 7).

Os níveis de glicemia se elevaram no pós-operatório em ambos os grupos, principalmente nos pacientes do Grupo I (que receberam corticóide). Quando realizada a comparação entre os dois grupos, em cada tempo, os níveis de glicemia só foram significativos $(p<0,001)$ nas amostras colhidas no pós-operatório imediato $(\mathrm{A} 2)$ e no $1^{\circ}$ dia de pósoperatório (A3), sendo o Grupo I > Grupo II.

A velocidade de hemossedimentação (VHS) em todos os pacientes apresentou uma queda durante a CEC (A2 e A3) e um aumento gradual após a CEC (A4), atingindo valores iguais ou até mesmo mais elevados que o inicial, nas amostras colhidas com 12 horas de PO (A5). Quando realizada a comparação dos dois grupos pela média de cada amostra, não houve diferença estatisticamente significativa entre os dois grupos.

TABELA 2

USO DE DROGAS VASOATIVAS (INOTROPICAS POSITI-

VAS) EM PACIENTES REVASCULARIZADOS COM

CIRCULACÃO EXTRACORPÓREA, UTILIZANDO

METILPREDNISOLONA (GRUPO I) OU SEM METILPREDNISOLONA (GRUPO II)

\begin{tabular}{ccccc}
\hline \multicolumn{5}{c}{ DROGAS VASOATIVAS } \\
CEC & SIM & NÃO & TOTAL & \% USO DROGAS \\
\hline Grupo I & 5 & 10 & 15 & 33,33 \\
Grupo II & 11 & 4 & 15 & 73,33 \\
\hline TOTAL & 16 & 14 & 30 & 53,33 \\
\hline
\end{tabular}

GRÁFICO 4

VALORES MÉDIOS DA TEMPERATURA (GRAUS CELSIUS)

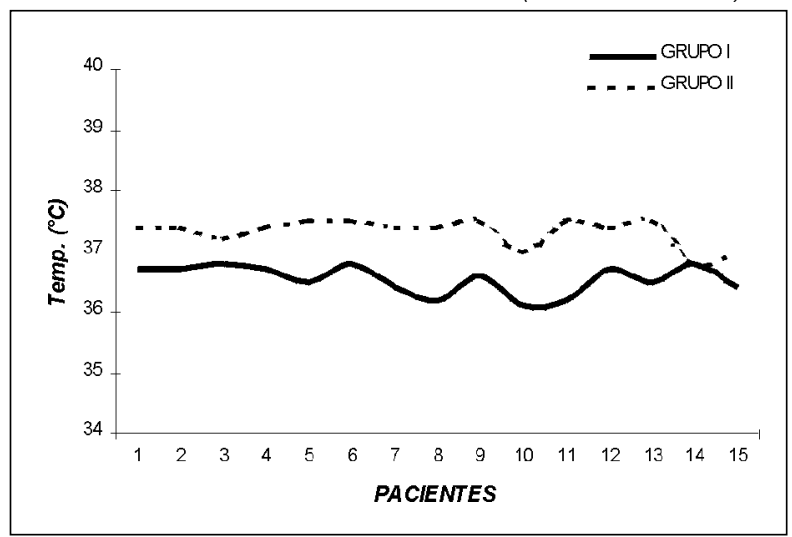

Nesta série de 30 pacientes selecionados para este estudo, portadores de insuficiência coronária e que foram submetidos à operação de revascularização do miocárdio com circulação extracorpórea, a mortalidade hospitalar foi nula.

Um (3,3\%) paciente apresentou infarto agudo do miocárdio (IAM inferior) no pós-operatório, sem repercussão hemodinâmica. Neste paciente, além da revascularização da coronária direita com enxerto de veia safena, foi necessária a realização de endarterectomia.

Não ocorreram complicações cerebrais, renais, hemorrágicas ou infecciosas. Todos os pacientes evoluíram com ausência de infecções ou deiscências, apresentando boa cicatrização das incisões cirúrgicas.

\section{COMENTÁRIOS}

A resposta inflamatória sistêmica induzida pela CEC é uma seqüência de eventos que envolve praticamente todas as células do corpo, na iniciação

GRÁFICO 5

TOTAL DE SANGRAMENTO PÓS-OPERATÓRIO (MILILITROS)

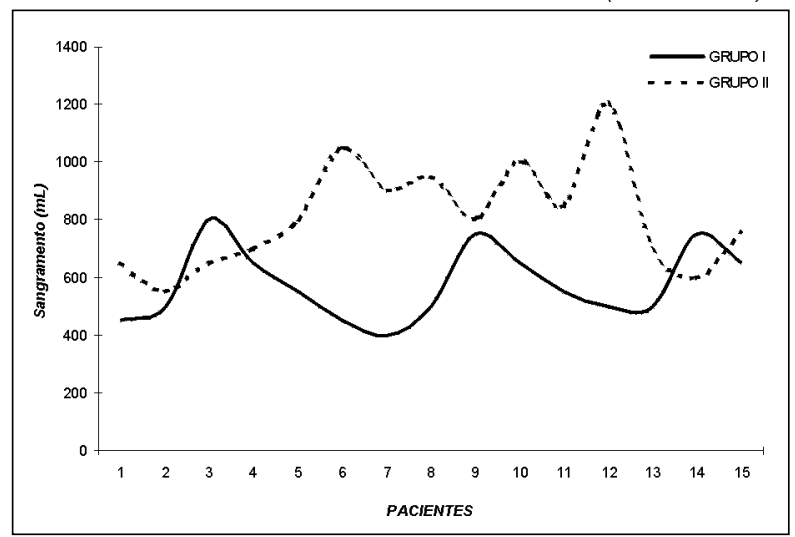


Brasil L A, Gomes W J, Salomão R, Fonseca J H P, Branco J N R, Buffolo E - Uso de corticóide como inibidor da resposta inflamatória sistêmica induzida pela circulação extracorpórea. Rev Bras Cir Cardiovasc 1999; 14 (3): 254-68.

GRÁFICO 6

TEMPO TOTAL DE INTUBAÇÃO OROTRAQUEAL

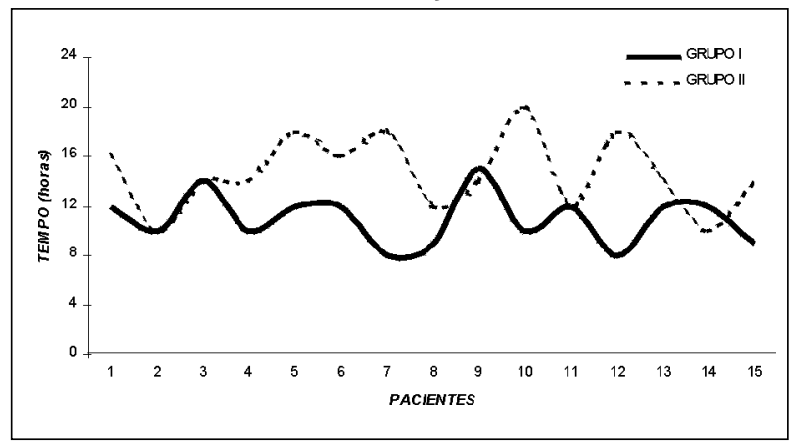

GRÁFICO 7

VALORES MÉDIOS DE LEUCÓCITOS / AMOSTRA $\left(\mathrm{mm}^{3}\right)$

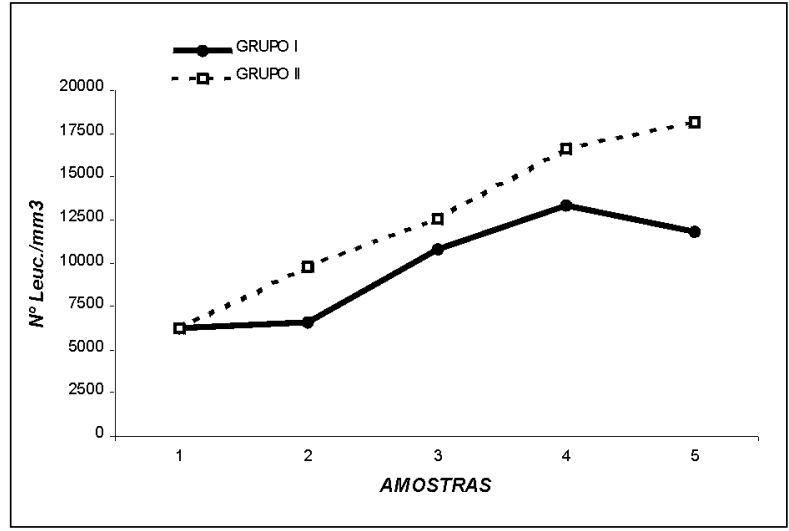

e propagação dessa importante resposta homeostática. Após a agressão, o organismo reage ativando mecanismos de defesa no sentido de proteger o tecido afetado e destruir o agente agressor, dando início ao que chamamos de inflamação(21,22).

A reação do sistema plasmático e celular, decorrente da ativação do sistema complemento ou por ação de endotoxinas, determina a liberação de substâncias pró-inflamatórias, que atuam como mediadores e marcadores da resposta inflamatória, produzindo alterações do fluxo sangüíneo e aumentando a permeabilidade vascular e a aderência dos leucócitos ao endotélio, causando lesão endotelial e conseqüente migração transendotelial dos leucócitos para os tecidos ${ }^{(14,22)}$

A ativação do sistema complemento, após o contato do sangue com as superfícies não biológicas (desprovidas de endotélio) do circuito extracorpóreo, com produção de anafilatoxinas (C3a e C5a) principalmente pela via alternativa, é considerada um dos principais fatores envolvidos na resposta inflamatória sistêmica induzida pela $\mathrm{CEC}^{(23)}$.

A liberação de C5a estimula a produção de citocinas e a ativação dos neutrófilos, levando ao aumento da permeabilidade vascular e ao extravasamento de líquidos para o interstício(24).

O contato do sangue com a superfície artificial do circuito da CEC pode também ativar o fator XII (fator Hangeman) e este, pela via intrínseca, ativa a cascata da coagulação. A cascata de calicreínas e a fibrinólise também são ativadas pelo fator XIla(1,25). Ocorre produção de bradicinina após a ativação das calicreínas, causando vasodilatação e aumento da permeabilidade vascular. Seus níveis permanecem elevados durante e após a CEC, pela exclusão da circulação pulmonar, que é o local principal de metabolização da bradicinina ${ }^{(6,26)}$.

Os produtos gerados pela degradação do fibrinogênio podem prejudicar a formação de fibrina, a função plaquetária e causar lesão endotelial. A combinação destes efeitos pode levar à lesão capilar, com alterações da hemostasia, determinando maior perda sangüínea ${ }^{(6,25)}$.

As endotoxinas são lipopolissacárides (LPS) derivados das paredes das bactérias em degradação. Seus efeitos biológicos incluem a ativação do sistema complemento, da cascata da coagulação ou de ambos, sendo um caminho alternativo para a liberação de radicais livres em resposta à ativação dos neutrófilos e ao aumento da adesividade das células endoteliais ${ }^{(6,7)}$.

A presença de endotoxinas na CEC pode ser devida à infusão de substâncias pirogênicas durante a operação ou pela utilização de materiais não estéreis do circuito extracorpóreo ou instrumental cirúrgico ${ }^{(9,27)}$.

Outros autores relataram a presença de endotoxinas na CEC como decorrente de isquemia da mucosa intestinal relacionada com a duração do pinçamento aórtico ou da própria circulação extracorpórea, onde ocorreria uma exposição dos órgãos a um período mais prolongado de fluxo não pulsátil da CEC, determinando principalmente vasoconstricção e conseqüente isquemia de órgãos do território esplâncnico. Esta endotoxinemia seria devida à translocação de bactérias gram negativas do intestino ocasionada por quebra da barreira da mucosa intestinal, que em condições normais impede a passagem de componentes tóxicos da luz intestinal para a corrente sangüínea(28).

Durante os últimos anos consideráveis progressos têm sido observados, no sentido de melhor compreensão dos mecanismos envolvidos nas reações induzidas pelas endotoxinas. O reconhecimento de que células do sistema reticuloendotelial medeiam a atividade tóxica das endotoxinas colocaram os macrófagos em foco de interesse ${ }^{(29)}$.

Os macrófagos são leucócitos com capacidade fagocítica que apresentam um único núcleo não seg- 
Brasil L A, Gomes W J, Salomão R, Fonseca J H P, Branco J N R, Buffolo E - Uso de corticóide como inibidor da resposta inflamatória sistêmica induzida pela circulação extracorpórea. Rev Bras Cir Cardiovasc 1999; 14 (3): 254-68.

mentado. Os macrófagos fixos nos tecidos podem ter nomes diferentes, mas são células que desempenham a mesma função. Assim, as células de Kupffer, a micróglia e os osteclastos nada mais são do que macrófagos fixos no fígado, cérebro e ossos, respectivamente ${ }^{(30)}$.

Os macrófagos interagem com o meio externo através de numerosos receptores de membrana. A ocupação destes receptores por substâncias agonistas induz intensas modificações no macrófago: migração da célula em direção a uma substância (quimiotaxia), movimentos localizados da membrana em direção a receptores de contato (adesão / marginação / fagocitose), síntese de sistemas enzimáticos para atividade antimicrobiana (ativação macrofágica). Eles constituem a primeira linha de defesa contra infecções após as barreiras naturais da pele e mucosas, secretando uma variedade de substâncias que produzem febre e aumento das proteínas da fase aguda do processo inflamatório (mediadores inflamatórios), como o TNF $\alpha$, IL-1, IL-6, IL-8, radicais superóxidos e óxido nítrico(30).

O Fator de Necrose Tumoral alfa (TNF $\alpha$ ) ou cachexina é uma glicoproteína, não imunoglobulina, liberada por células vivas do hospedeiro e que agem não enzimaticamente, regulando diversas funções celulares.

Segundo AGGARWAL et al. (31) o TNF $\alpha$ é um hormônio polipeptídeo de $17 \mathrm{KDa}$ (quilodaltons) na sua forma livre. Sua produção é regulada predominantemente em nível pós-transcricional, após a formação do RNA mensageiro (RNAm), sendo que, após o estímulo com LPS, há um aumento de 100 vezes na quantidade deste RNA e mais de 10.000 vezes da proteína liberada(32). Esse controle póstranscrição pode ser em parte exercido pela presença na porção 3' não traduzida da molécula do RNAm do $T N F \alpha$, de uma seqüência repetida de bases nitrogenadas, Uridina(U) e $\operatorname{Adenosina(A),~que~pare-~}$ ce exercer um papel regulador da expressão genética da citocina(33).

TNF $\alpha$ é produzido principalmente pelos macrófagos. Outras células também produzem TNF $\alpha$ como os linfócitos T, mastócitos, células endoteliais, células de Langerhans, astrócitos, células natural Killer, mast cells e células do músculo liso ${ }^{(31,34)}$.

Vários estímulos como as endotoxinas, a porção C5a do complemento, partículas virais e os fungos, são capazes de induzir a produção de TNF $\alpha$ pelos macrófagos. Dentre esses, o LPS é o mais potente $e^{(34,35)}$.

Após a indução pelo LPS, o TNF $\alpha$ é rapidamente sintetizado, ocorrendo elevação do nível plasmático após $20 \mathrm{~min}$, com pico entre 60 e $90 \mathrm{~min}$, não sendo mais detectável após $4 \mathrm{~h}{ }^{36}$.
A liberação de TNF $\alpha$ resulta no aparecimento de vários efeitos como febre, leucocitose, alterações da barreira endotelial resultando no aumento de líquido intersticial, coagulopatia, comprometimento da função pulmonar e do sistema cardiovascular, levando à depressão miocárdica e ao aumento da resistência vascular sistêmica (vasodilatação), ocasionando taquicardia e hipotensão arterial( $14,37,38)$.

São conhecidos dois receptores específicos para o TNF $\alpha$, sendo um de 55KDa (TNF-R1), encontrados principalmente em células epiteliais e que respondem preferencialmente pelos efeitos de citólise e citotoxidade. Já os receptores maiores, de $75 \mathrm{KDa}$ (TNF-R2) localizam-se predominantemente em células linfóides e produzem principalmente proliferação celular ${ }^{(30,39)}$. Eles variam de 200 a 5.000 moléculas/célula e são responsáveis pela rápida eliminação da proteína da corrente sangüínea(31,34).

Receptores solúveis de TNF $\alpha$ foram descritos funcionando como reguladores da atividade biológica desta citocina(40).

A produção e a atividade biológica do TNF $\alpha$ é influenciada por outras citocinas. A IL-1 e o TNF $\alpha$ agem sinergicamente na produção de choque em modelos experimentais e também estimulando a produção e liberação de outras citocinas, como a IL-6 e a IL-8. A IL-4, IL-6 e a IL-10 bloqueiam a atividade TNF $\alpha^{(13-15)}$.

O TNF $\alpha$ juntamente com a IL-1 interfere também na regulação da homeostasia do óxido nítrico, determinando aumento na produção do fator relaxante derivado do endotélio, contribuindo para a vasodilatação que ocorre durante e após a $\operatorname{CEC}^{(41,42)}$.

A supressão dos efeitos do TNF $\alpha$ é mediada por corticóide $^{(30,43)}$ e por pentoxifilina $(44,45)$.

A interleucina 6 (IL-6) é uma citocina de 21 a $28 \mathrm{KDa}$ que foi inicialmente descrita como interferon beta subtipo 2 (IF- $\left.\beta_{2}\right)$, fator de diferenciação de células $B$, "favorecedor" de produção de imunoglobulina $A$, fator de crescimento de hibridomas de células $B$ e fator estimulador de hepatócitos ${ }^{(46)}$. A IL-6 é produzida por várias células como os macrófagos, fibroblastos, células $T$ e $B$, queratinócitos, mast cells e também por células endoteliais $^{(47)}$.

A liberação de IL-6 é estimulada pelas endotoxinas, pelo TNF $\alpha$ e pela interleucina $1^{(47,48)}$.

Após o estímulo com LPS a IL-6 é rapidamente liberada, podendo ser detectada na circulação dentro de $60 \mathrm{~min}$, com níveis séricos atingindo pico com $2 \mathrm{~h}$, permanecendo detectável por até $20 \mathrm{~h}$ (49).

A IL-6 tem função biológica variada, estimulando o crescimento e diferenciação de células $B$ e 
Brasil L A, Gomes W J, Salomão R, Fonseca J H P, Branco J N R, Buffolo E - Uso de corticóide como inibidor da resposta inflamatória sistêmica induzida pela circulação extracorpórea.

Rev Bras Cir Cardiovasc 1999; 14 (3): 254-68.

induzindo a síntese de proteínas de fase aguda no fígado. Interage com outras citocinas aumentando a expressão de receptores de IL-2 e a produção desta citocina por células $\mathrm{T}$, tendo efeito inibidor sobre a produção de $\operatorname{TNF} \alpha^{(50)}$. Devido à sua atividade biológica, a IL-6 funciona como um marcador da intensidade inflamatória, estando seus níveis séricos relacionados com a morbimortalidade, decorrentes do uso da $\operatorname{CEC}^{(54-56)}$

Em estudo experimental(52) foi demonstrado os efeitos inotrópicos negativos de citocinas (TNF $\alpha$, IL2 e IL-6) mediados pelo óxido nítrico. Em seguida, FINKEL et al. (53) relacionaram os níveis séricos de IL-6 com a presença de falência miocárdica verificada após a CEC, e concluíram que a IL-6 poderia ser responsável pela falência miocárdica e enfatizaram o valor prognóstico da mensuração dos níveis desta citocina após a CEC.

O reconhecimento de que as citocinas agem como um dos principais mediadores e marcadores da intensidade da resposta inflamatória induzida pela circulação extracorpórea, fez com que vários autores investigassem formas (intervenções terapêuticas) para atenuar ou mesmo suprimir seus efeitos, visando com isto diminuir os efeitos sistêmicos adversos decorrentes do uso da $\operatorname{CEC}^{(54-56)}$.

O emprego de hemofiltros durante a CEC é relatado na literatura com a finalidade de retirar as citocinas da circulação, visando à diminuição da resposta inflamatória induzida pela $\operatorname{CEC}^{(57,58)}$.

O uso de circuitos de circulação extracorpórea revestidos com heparina também tem sido demonstrado na literatura com o objetivo de diminuir a resposta inflamatória pós-CEC ${ }^{(59,60)}$.

A descontaminação seletiva do tracto gastrointestinal, com a administração de antibióticos via oral pré-CEC, também foi preconizada, com o objetivo de reduzir a endotoxinemia durante e após a CEC, visando à diminuição da produção de citocinas, da ativação do sistema complemento e a subseqüente diminuição da resposta inflamatória pós$\operatorname{CEC}^{(61,62)}$.

Tentativas terapêuticas de bloquear os efeitos das citocinas através de anticorpos monoclonais ou pelo bloqueio de receptores específicos têm sido demonstradas por vários pesquisadores, no sentido de atenuar ou suprimir os efeitos deletérios da $\operatorname{CEC}^{(63,64)}$.

Várias drogas como a pentoxifilina ${ }^{(6,65)}$, indometacina ${ }^{(66)}$ e a aprotinina ${ }^{(67)}$ também têm sido usadas com o intuito de reduzir a resposta inflamatória causada pelo uso da CEC.

Em 1986, ENGLAND et al. ${ }^{(68)}$ demonstraram que o uso de anti-oxidantes, como o manitol e o alupu- rinol, pode diminuir a produção de radicais livres durante e após a CEC.

O uso de corticóide tem sido relatado na literatura como uma alternativa eficaz, visando diminuir os efeitos sistêmicos causados pela liberação de citocinas durante e após a $\operatorname{CEC}^{(69,70)}$.

Os corticosteróides foram usados desde a década de 60, embora nesta época ainda não se entendia os mecanismos pelos quais eles poderiam agir no sentido de diminuir a resposta inflamatória sistêmica induzida pela CEC $^{(71)}$.

Estudos realizados na década de 70 demonstraram que a administração de metilprednisolona no tratamento da síndrome de baixo débito após intervenção cardíaca com CEC ocasionava um significante aumento do índice cardíaco, com melhora do fluxo sangüíneo coronariano e diminuição da resistência vascular periférica(72-74).

FEY et al. ${ }^{(75)}$ observaram que os corticóides protegiam o coração contra a depressão miocárdica provocada pela isquemia, estabilizando a membrana dos lisossomas, com conseqüente diminuição da autólise celular, proporcionando o aumento de células miocárdicas viáveis

Em 1986, BEUTLER et al. ${ }^{(76)}$, ao estudarem os mecanismos de controle da síntese do TNF $\alpha$, avaliaram os efeitos da dexametasona na produção de citocina e do seu RNA mensageiro. A dexametasona é capaz de suprimir a transcrição e tradução (síntese da proteína), estimuladas pelo LPS. Contudo, se a fase pós transcrição estiver em andamento, a dexametasona não impede o processo da síntese do peptídeo, ou seja, os corticosteróides determinam redução da produção de TNF $\alpha$ apenas quando administrados previamente à estimulação do macrófago.

O uso rotineiro de corticóide profilaticamente antes da CEC ainda não é conduta bem estabelecida.

Está descrita na literatura a diminuição da ativação do sistema complemento durante a CEC pelo tratamento prévio com corticosteróides $(77,78)$.

É relatado também que a metilprednisolona, além de atuar nos leucócitos do sangue periférico, altera a quantidade total de polimorfonucleares no fluído do lavado bronco-alveolar, melhorando a função pulmonar de pacientes submetidos à operação cardíaca com CEC ${ }^{(79)}$.

Foi demonstrado por JANSEN et al. (80) que o uso profilático de dexametasona em operação de revascularização do miocárdio com CEC reduz a liberação de TNF $\alpha$, do leucotrieno B4 e também do fator ativador de plasminogênio. Nestes pacientes tratados com corticóide, observou-se menor hipertermia, menos leucocitose, menor instabilidade hemo- 
Brasil L A, Gomes W J, Salomão R, Fonseca J H P, Branco J N R, Buffolo E - Uso de corticóide como inibidor da resposta inflamatória sistêmica induzida pela circulação extracorpórea. Rev Bras Cir Cardiovasc 1999; 14 (3): 254-68.

dinâmica e, conseqüentemente, menor necessidade do uso de drogas vasoativas.

Ao analisar os resultados do presente trabalho comparando os pacientes do Grupo I (que receberam corticóide antes da CEC) com os pacientes do Grupo II (que não receberam corticóide), verificamos que aqueles do Grupo I apresentaram menor liberação de citocinas pró-inflamatórias (TNF $\alpha$ e IL$6)$, evoluíram com pressão arterial mais elevada $(7,9 \pm 0,5$ vs $7,3 \pm 0,4 \mathrm{mmHg})$, menor taquicardia $(105,6 \pm 5,9$ vs $109,3 \pm 7,2 \mathrm{bpm})$ e menos hipertermia $\left(36,5 \pm 0,2\right.$ vs $\left.37,3 \pm 0,2^{\circ} \mathrm{C}\right)$. Também necessitaram de menos drogas vasoativas ( 5 vs 11 ), tiveram menor sangramento pós-operatório (576,6 4 119,5 vs 810,0 $\pm 176,2 \mathrm{ml}$ ), menor tempo de intubação oro-traqueal $(11,0 \pm 2,0$ vs $14,6 \pm 2,9$ hs) e apresentaram leucocitose menos acentuada.

Estes resultados estão de acordo com aqueles descritos no estudo de JANSEN et al. ${ }^{(80)}$.

Em 1995, ENGELMAN et al. ${ }^{(81)}$ relataram que a administração profilática de metilprednisolona e dexametasona em pacientes submetidos à operação cardíaca com CEC pode produzir uma diminuição acentuada dos níveis de complemento e também de citocinas, com ausência de reações adversas devido ao uso de esteróides.

Nesse mesmo ano, TEOH et al. ${ }^{(82)}$ demonstraram que a administração de metilprednisolona antes da CEC reduz acentuadamente a liberação de TNF $\alpha$, IL-6 e IL- 8 . Esses autores concluíram que, quando esteróides são administrados profilaticamente antes da CEC normotérmica ocasionam um bloqueio na liberação de citocinas e na vasodilatação pós-operatória.
TABARDEL et al. ${ }^{(83)}$, em 1996, demonstraram que a administração profilática de corticóide diminui a liberação de citocinas pró-inflamatórias, como também aumenta a liberação de IL-10, que é uma citocina antiinflamatória.

Outro estudo que comparou a administração de corticóide antes e após a CEC foi realizado em 1997 por WAN et al. (84) em pacientes submetidos a transplante cardíaco ou cardiopulmonar. Evidenciaram que o uso de corticóide antes da CEC reduz significantemente a produção de TNF $\alpha$ e IL-8.

Estes estudos mostram resultados semelhantes aos encontrados nesta pesquisa, demonstrando a eficácia do uso profilático de corticóide na redução da liberação de citocinas pró-inflamatórias e, conseqüentemente, na diminuição da resposta inflamatória induzida pela CEC.

\section{CONCLUSÕES}

A metilprednisolona inibiu significantemente a liberação de citocinas pró-inflamatórias, principalmente o TNF $\alpha$.

Os efeitos sistêmicos adversos decorrentes da resposta inflamatória pós-CEC foram atenuados com o uso de corticóide.

Com base em nossos resultados, acreditamos que o uso profilático e rotineiro de metilprednisolona pode ser uma opção terapêutica, visando à diminuição da morbidade pós-operatória decorrente do uso da CEC. 
Brasil L A, Gomes W J, Salomão R, Fonseca J H P, Branco J N R, Buffolo E - Uso de corticóide como inibidor da resposta inflamatória sistêmica induzida pela circulação extracorpórea. Rev Bras Cir Cardiovasc 1999; 14 (3): 254-68.

RBCCV 44205-467

Brasil L A, Gomes W J, Salomão R, Fonseca J H P, Branco J N R, Buffolo E - Corticoid as an inhibitor of systemic inflammatory response, induced by cardiopulmonary bypass. Rev Bras Cir Cardiovasc 1999; 14 (3): 254-68.

ABSTRACT: Cardiopulmonary bypass (CPB) induces the development of a systemic inflammatory response syndrome, with the release of cytokines that are responsible for many clinical manifestations.

Purpose: The purpose of the study was to observe the release of the cytokines - tumor necrosis factor alpha (TNF $\alpha$ ) and Interleukine-6 (IL-6), and to verify the clinical alterations produced in patients undergoing myocardial revascularization with CPB, with or without corticoids.

Material and Methods: Thirty patients were studied - 15 used corticoid (methylprednisolone, $30 \mathrm{mg} / \mathrm{kg}$ Group I) and 15 did not (Group II). Serial blood samples were collected and the TNF $\alpha$ and IL-6 release were analyzed, as well as the leukocyte count, erythrocyte sedimentation rate and glycemia. The blood pressure, cardiac rate, temperature, postoperative bleeding, orotracheal tubing time and inotropic drug requirement were also compared. Statistical significance was assumed when $p \leq 0.05$.

Results: In Group I TNF $\alpha$ was not detected and IL- 6 was detected in 13 patients, with levels ranging from 8.6 to $101.8 \mathrm{pg} / \mathrm{ml}$. In Group II TNF $\alpha$ was detected in 13 patients, with levels between 5.4 and $231.0 \mathrm{pg} / \mathrm{ml}$. The IL-6 in this group was detected in 15 patients, with higher levels than those in Group I, varying between 5.5 and $2569.0 \mathrm{pg} / \mathrm{ml}$. The Group I patients had higher medium blood pressure $(7.9 \pm 0.5 \mathrm{vs} 7.3 \pm 0.4 \mathrm{mmHg})$ and lower inotropic drug requirement ( 5 vs 11). They evolved with less tachycardia (105.6 \pm 5.9 vs $109.3 \pm 7.2 \mathrm{bpm}$ ), lower temperature $\left(36.5 \pm 0.2 \mathrm{vs} 37.3 \pm 0.2^{\circ} \mathrm{C}\right)$, lower postoperative bleeding, $(576.6 \pm 119.5 \mathrm{vs} 810.0 \pm 176.2 \mathrm{ml})$, shorter orotracheal tubing time $(11.0 \pm 2.0 \mathrm{vs} 14.6 \pm 2.9 \mathrm{hs})$ and lower leukocytosis. The glycemia level was just significant (Group I > Grupo II) in the immediate postoperative and in the first postoperative samples. The erythrocyte sedimentation rate did not present significant statistical difference between the two groups.

Conclusion: The methylprednisolone significantly inhibited the release of inflammatory cytokines mainly the TNF $\alpha$. The systemic adverse effects caused by the inflammatory response after CPB were minimized by corticoid use.

DESCRIPTORS: Myocardial revascularization. Extracorporeal circulation,adverse effect. Corticoids, farmacology. Sepsis syndrome, etiology. IL6, antagonists \& inhibitors. TNF-alpha, antagonists \& inhibitors.

\section{REFERÊNCIAS BIBLIOGRÁFICAS}

1 Kirklin J K, George J F, Holman W - The inflammatory response to cardiopulmonary bypass. In: Gravile G, Davis RF, Utley JR, eds. Cardiopulmonary bypass: principles and practice. Baltimore: Williams \& Wilkins, 1993: 233-48.

2 Westaby S - Organ dysfunction after cardiopulmonary bypass: a systemic inflammatory reaction by the extracorporeal circuit. Intensive Care Med 1987; 13: 89-95.

3 Bone R C, Balk R A, Cerra F B, Dellinger R P et al. Definitions for sepsis and organ failure and guidelines for the use of innovative therapies in sepsis. Chest 1992; 101: 1644-55.

4 Taylor K M - SIRS: the systemic inflammatory response syndrome after cardiac operations. Ann Thorac Surg 1996; 61: 1607-8 (Editorial).

5 Boyle J R, Pohlman T H, Cornejo C J, Verrier E D Ischemia-reperfusion injury. Ann Thorac Surg 1996; 64: S24-30.

6 Butler J, Rocker G M, Westaby S - Inflammatory response to cardiopulmonary bypass. Ann Thorac Surg 1993; 55: $552-9$.
7 Dofferhoff A S, Jong H J, Bom V J et al. - Complement activation and the production of inflammatory mediators during the treatment of severe sepsis in humans. Scand J Infect Dis 1992; 24: 197-204.

8 Casey L C, Balk R A, Bone R C - Plasma cytokine and endotoxin levels correlate with survival in patients with the sepsis syndrome. Ann Intern Med 1993; 119: 771-8.

9 Rocke D A, Gaffin S L, Wells M T, Koen Y, Brock-Utine J G - Endotoxemia associated with cardiopulmonary bypass. J Thorac Cardiovasc Surg 1987; 93: 832-7.

10 Nilsson L, Kulander L, Nystrom S O, Eriksson O Endotoxins in cardiopulmonary bypass. J Thorac Cardiovasc Surg 1990; 100: 777-80.

11 Lowry S F - Cytokines mediators of immunity and inflammation. Arch Surg 1993; 128: 1235-41.

12 Cremer J, Martin M, Redl H et al. - Systemic inflammatory response syndrome after cardiac operations. Ann Thorac Surg 1996; 61 :1714-20.

13 Nathan C \& Sporn M - Cytokines in context. J Cell Biol $1991 ; 113: 981-6$.

14 Roitt I, Brostoff J, Male D - Immunology. $4^{\text {th }}$ ed. London: Mosby, 1996:420p. 
Brasil L A, Gomes W J, Salomão R, Fonseca J H P, Branco J N R, Buffolo E - Uso de corticóide como inibidor da resposta inflamatória sistêmica induzida pela circulação extracorpórea. Rev Bras Cir Cardiovasc 1999; 14 (3): 254-68.

15 Fahey T J III \& Tracey K J - Cytokines, tumor necrosis factor and other mediators of sepsis. In: Carlson RW \& Geheb MA, eds. Principles \& practice of medical intensive care. Philadelphia: WB Saunders, 1993: 311-23.

16 Moat N E, Shore D F, Evans T W - Organ dysfunction and cardiopulmonary bypass: the role of complement and complement regulatory proteins. Eur $J$ Cardiothorac Surg 1993; 7: 563-73.

17 Frering B, Philip I, Dehoux M, Rolland C, Langlois J M, Desmonts $\mathrm{J}$ M - Circulating cytokines in patients undergoing normothermic cardiopulmonary bypass. $J$ Thorac Cardiovasc Surg 1994; 108: 636-41.

Holzheimer R G, Molloy R G, Gorlach H, Wilkert S, Hehrlein F - IL6 and TNF-alpha release in association with neutrophil activation after cardiopulmonary bypass surgery. Infection 1994; 22: 37-42.

19 Hennein HA, Ebba H, Rodriguez JL et al. - Relationship of the proinflammatory cytokines to myocardial ischemia and dysfunction after uncomplicated coronary revascularization. J Thorac Cardiovasc Surg 1994; 108: 626-35

20 Brasil L A, Gomes W J, Salomão R, Buffolo E Inflammatory response after myocardial revascularization with or without cardiopulmonary bypass. Ann Thorac Surg 1998; 66: 56-9.

21 Baulmann H \& Gaudie J - The acute phase response. Immunol Today 1994; 15: 74-80.

Hill G E - The inflammatory response to cardiopulmonary bypass. Int Anesthesiol Clin 1996; 34: 95-108.

23 Kirklin J K - The postperfusion syndrome: inflammation and damaging effects of cardiopulmonary bypass. In: Tinker JH, ed. Cardiopulmonary bypass: current concepts and controversies. Philadelphia: WB Saunders, 1989: 131-46.

24 Butler J, Chong G L, Baigrie R J, Pillai R, Westaby S, Rocker G M - Cytokine responses to cardiopulmonary bypass with membrane and bubble oxygenation. Ann Thorac Surg 1992; 53: 833-8.

Bachmann F, McKenna R, Cole E R, Najafi H - The hemostatic mechanism after open-heart surgery: I. Studies on plasma coagulation factors and fibrinolysis in 512 patients after extracorporeal circulation. $J$ Thorac Cardiovasc Surg 1975; 70: 76-85.

Pang L M, Stalcup S A, Lipset J S, Hayes C J, Bowman F O Jr, Mellins R B - Increased circulating bradykinin during hypothermia and cardiopulmonary bypass in children. Circulation 1979; 60: 1503-7.

27 Casey W F, Hauser G J, Hannallah R S, Midgley F M, Khan W N - Circulating endotoxin and tumor necrosis factor during pediatric cardiac surgery. Crit Care Med 1992; 20: 1090-6.

28 Riddington D W, Venkatesh B, Boivin C M et al. - Intes- tinal permeability, gastric intramucosal $\mathrm{pH}$, and systemic endotoxemia in patients undergoing cardiopulmonary bypass. JAMA 1996; 275: 1107-12.

29 Beutler B, Mahoney J, Trang N L, Pekala P, Cerami A - Purification of cachectin, a lipoprotein lipasesuppressing hormone secreted by endotoxin-induced RAW 264.7 cells. J Exp Med 1985; 161: 984-95.

30 Akamine N, Fernandes Jr C J, Wey S B, Knobel E Choque séptico e mecanismos de agressão tecidual. In: Knobel E, ed. Condutas no paciente grave. $2^{\mathrm{a}} \mathrm{ed}$. São Paulo: Atheneu, 1998:17-46.

31 Aggarwal B B, Kohr W J, Hass P E et al. - Human tumor necrosis factor: production, purification, and characterization. J Biol Chem 1985; 260: 2345-54.

32 Beutler B - TNF in pathophysiology: biosynthetic regulation. J Invest Dermatol 1990; 95 (6 Suppl): S81-4.

33 Caput D, Beutler B, Hartog K, Thayer R, Brown-Shimer $S$, Cerami A - Identification of a common nucleotide sequence in the 3'-untranslated region of mRNA molecules specifying inflammatory mediators. Proc Natl Acad Sci USA 1986; 83: 1670-4.

34 Beutler B A, Milsark I W, Cerami A - Cachectin / tumor necrosis factor: production, distribution and metabolic fate in vivo. J Immunol 1985; 135: 3972-7.

35 Offner F, Philippe J, Vogelaers D et al. - Serum tumor necrosis factor levels in patients with infections disease and septic shock. J Lab Clin Med 1990; 116: 100-5.

36 Michie H R, Manogue K R, Spriggs D R et al. - Detection of circulating tumor necrosis factor after endotoxin administration. N Engl J Med 1988; 318: 1481-6.

37 Bernard C \& Tedgui A - Cytokine network and the vessel wall: insights into septic shock pathogenesis. Eur Cytokine Netw 1992; 3: 19-33.

38 Jansen $\mathrm{N} \mathrm{J}$, van Oeveren $\mathrm{W}, \mathrm{Gu} \mathrm{Y} \mathrm{J}$, van Vliet $\mathrm{M} \mathrm{H}$, Eijsman L, Wildevuur C R - Endotoxin release and tumor necrosis factor formation during cardiopulmonary bypass. Ann Thorac Surg 1992; 54: 744-8.

39 Tartaglia L A, Weber R F, Figari I S, Reynolds C, Palladino MA Jr, Goeddell D V- The two different receptors for tumor necrosis factor mediate distinct cellular responses. Proc Natl Acad Sci USA 1991; 88: 9292-6.

40 Mohler K M, Torrance D S, Smith C A et al. - Soluble tumor necrosis factor(TNF) receptors are effective therapeutic agents in lethal endotoxemia and function simultaneously as both TNF carriers and TNF antagonists. J Immunol 1993; 151: 1548-61.

41 Menasché $P$ - The inflammatory response to cardiopulmonary bypass and its impact on postoperative myocardial function. Current Opin Cardiol 1995; 10: 597-604.

42 Tassiopoulos A K, Carlin R E, Gao Y et al. - Role of nitric 
Brasil L A, Gomes W J, Salomão R, Fonseca J H P, Branco J N R, Buffolo E - Uso de corticóide como inibidor da resposta inflamatória sistêmica induzida pela circulação extracorpórea. Rev Bras Cir Cardiovasc 1999; 14 (3): 254-68.

oxide and tumor necrosis factor on lung injury caused by ischemia / reperfusion of the lower extremities. $J$ Vasc Surg 1997; 26: 647-56.

43 Waage A \& Bakke O - Glucocorticoids suppress the production of tumor necrosis factor by lipopolysaccharide-stimulated human monocytes. Immunology 1988; 63: 299-302.

44 Lilly C M, Sandhu J S, Ishizaka A et al. - Pentoxifylline prevents tumor necrosis factor-induced lung injury. Am Rev Respir Dis 1989; 139: 1361-8.

45 Noel P, Nelson S, Bokulic R et al. - Pentoxifylline inhibits lipopolysaccharide-induced serum tumor necrosis factor and mortality. Life Sci 1990; 47: 1023-9.

46 Kishimoto T - The biology of interleukin-6. Blood 1989; 74: 1-10.

47 Van Snick J - Interleukin-6: an overview. Annu Rev Immunol 1990; 8: 253-78.

48 Shalaby M R, Waage A, Aarden L, Espevik T - Endotoxin, tumor necrosis factor-alpha and interleukin-1 induce interleukin-6 production in vivo. Clin Immunol Immunopathol 1989; 53: 488-98.

49 Fong $Y$, Moldawer L L, Shires G T, Lowry S F - The biologic characteristics of cytokines and their implications in surgical injury. Surg Gynecol Obstet 1990; 170: 363-78.

50 Akira S, Taga T, Kishimoto T - Interleukin-6 in biology and medicine. Adv Immunol 1993; 54: 1-78.

51 Levy J H \& Kelly A B - Inflammation and cardiopulmonary bypass. Can J Anaesth 1993; 40: 1009-15 (Editorial).

52 Finkel M S, Oddis C V, Jacob T D, Watkins S C, Hattler B G, Simmons R L - Negative inotropic effects of cytokines on the heart mediated by nitric oxide. Science 1992; 257: 387-9.

53 Finkel M S, Hoffman R A, Shen L, Oddis C V, Simmons R L, Hattler B G - Interleukin-6 (IL-6) as a mediator of stunned myocardium. Am J Cardiol 1993; 71: 1231-2.

54 Casey L C - Role of cytokines in the pathogenesis of cardiopulmonary-induced multisystem organ failure. Ann Thorac Surg 1993; 56 (5 Suppl): S92-6.

55 Brasil L A, Gomes W J, Salomão R, Buffolo E - Ativação de citocina (fator de necrose tumoral-a) e resposta clínica induzida pela circulação extracorpórea. Rev Bras Cir Cardiovasc 1996; 11: 188-200.

56 Savaris N - Resposta imunoinflamatória à circulação extracorpórea: estado atual. Rev Bras Anestesiol 1998; 48: 126-36.

57 Journois D, Pouard P, Greeley W J, Mauriat P, Vouhe $P$, Safran D - Hemofiltration during cardiopulmonary bypass in pediatric cardiac surgery: effects on hemostasis, cytokines, and complement components. Anesthesiology 1994; 81: 1181-9.

58 Millar A B, Armstrong L, van der Linden J et al. - Cytokine production and hemofiltration in children undergoing cardiopulmonary bypass. Ann Thorac Surg 1993; 56: 1499-502.

59 Gu Y J, van Oeveren W, Akkerman C, Boonstra P W, Huyzen R J, Wildevuur C R - Heparin-coated circuits reduce the inflammatory response to cardiopulmonary bypass. Ann Thorac Surg 1993; 55: 917-22.

60 Steinberg B M, Grossi E A, Schwartz D S et al. - Heparin bonding of bypass circuits reduces cytokine release during cardiopulmonary bypass. Ann Thorac Surg 1995; 60: 525-9.

61 Martinez-Pellús A E, Merino $\mathrm{P}, \mathrm{Bru} \mathrm{M}$ et al. - Can selective digestive decontamination avoid the endotoxemia and cytokine activation promoted by cardiopulmonary bypass? Crit Care Med 1993; 21: 1684-91.

62 Martinez-Pellús A E, Merino P, Bru M et al. - Endogenous endotoxemia of intestinal origin during cardiopulmonary bypass: role of type of flow and protective effect of selective digestive decontamination. Intensive Care Med 1997; 23: 1251-7.

63 Dinarello C A, Gelfand J A, Wolff S M - Anticytokine strategies in the treatment of the systemic inflammatory response syndrome. JAMA 1993; 269: 1829-35.

64 Boyle E M Jr, Pohlman T H , Johnson M C, Verrier E $D$ - Endothelial cell injury in cardiovascular surgery: the systemic inflammatory response. Ann Thorac Surg 1997; 63: 277-84.

65 Sullivan G W, Carper H T, Novick W J Jr, Mandell G L - Inhibition of the inflammatory action of interleukin1 and tumor necrosis factor(alpha) on neutrophil function by pentoxifylline. Infect Immun 1988; 56: 1722-9.

66 Markewitz A, Faist E, Lang S, Endres S, Hultner L, Reichart B - Regulation of acute phase response after cardiopulmonary bypass by immunomodulation. Ann Thorac Surg 1993; 55: 389-94.

67 Hill G E, Diego R P, Stammers A H, Huffman S M, Pohorecki R - Aprotinin enhances the endogenous release of interleukin-10 after cardiac operations. Ann Thorac Surg 1998; 65: 66-9.

68 England M D, Cavarocchi N C, O'Brien J F et al. Influence of antioxidants (mannitol and allopurinol) on oxygen free radical generation during and after cardiopulmonary bypass. Circulation 1986; 74 (5Pt2): III 134-7.

69 Hill G E, Alonso A, Thiele G M, Robbins R A - Glucocorticoids blunt neutrophil CD11b surface glycoprotein upregulation during cardiopulmonary bypass in humans. Anesth Analg 1994; 79: 23-7. 
Brasil L A, Gomes W J, Salomão R, Fonseca J H P, Branco J N R, Buffolo E - Uso de corticóide como inibidor da resposta inflamatória sistêmica induzida pela circulação extracorpórea. Rev Bras Cir Cardiovasc 1999; 14 (3): 254-68.

70 Inaba H, Kochi A, Yorozu S - Suppression by methylprednisolone of augmented plasma endotoxin-like activity and interleukin- 6 during cardiopulmonary bypass. Br J Anaesth 1994; 72: 348-50.

71 Moses M L, Camishion R C, Tokunaga K, Pierucci L Jr, Davies A L, Nealon T F Jr - Effect of corticosteroid on the acidosis of prolonged cardiopulmonary bypass. J Surg Res 1966; 6: 354-60.

72 Dietzman R H, Castañeda A R, Lillehei C W, Erser A, Motsay G J, Lillehei R C - Corticosteroids as effective vasodilators in the treatment of low output syndrome. Chest 1970; 57: 440-53.

73 Vinas J F, Fewel J G, Grover F L et al. - Effects of methylprednisolone on coronary blood flow and myocardial metabolism during cardiopulmonary bypass. Surgery 1977; 81: 646-52.

74 Niazi Z, Flodin P, Joyce L, Smith J, Mauer H, Lillehei R C - Effects of glucocorticosteroids in patients undergoing coronary artery bypass surgery. Chest 1979; 76: 262-8.

75 Fey K, Follette D, Livesay J et al. - Effects of membrane stabilization on the safety of hypothermic arrest after aortic cross-clamping. Circulation 1977; 56(3 Suppl II):143-7.

76 Beutler B, Krochin N, Milsark I W, Luedke C, Cerami A - Control of cachectin (tumor necrosis factor) synthesis: mechanisms of endotoxin resistance. Science 1986; 232: 977-80.

77 Hammerschmidt D E, Stroncek D F, Bowers T K et al.
- Complement activation and neutropenia occurring during cardiopulmonary bypass. J Thorac Cardiovasc Surg 1981; 81: 370-7.

78 Cavarocchi N C, Pluth J R, Schaff H V et al. - Complement activation during cardiopulmonary bypass: comparison of bubble and membrane oxygenators. J Thorac Cardiovasc Surg 1986; 91: 252-8.

79 Fosse E, Mollnes T E, Ingvaldsen B - Complement activation during major operations with or without cardiopulmonary bypass. J Thorac Cardiovasc Surg 1987; 93: 860-6.

80 Jansen $\mathrm{N} \mathrm{J}$, van Oeveren $\mathrm{W}$, van der Broek $\mathrm{L}$ et al. Inhibition by dexamethasone of the reperfusion phenomena in cardiopulmonary bypass. J Thorac Cardiovasc Surg 1991; 102: 515-25.

81 Engelman R M, Rousou J A, Flack J E 3rd, Deaton D W, Kalfin R, Das D K - Influence of steroids on complement and cytokine generation after cardiopulmonary bypass. Ann Thorac Surg 1995; 60: 801-4.

82 Teoh K H, Bradley C A, Gauldie J, Burrows H - Steroid inhibition of cytokine-mediated vasodilation after warm heart surgery. Circulation 1995;92(9 Suppl II):347-53.

83 Tabardel Y, Duchateau J, Schmartz D et al. - Corticosteroids increase blood interleukin-10 levels during cardiopulmonary bypass in men. Surgery 1996; 119: 76-80.

84 Wan S, LeClerc J L, Vincent J L - Cytokine responses to cardiopulmonary bypass: lessons learned from cardiac transplantation. Ann Thorac Surg 1997; 63: 269-76. 